\title{
Incidental Diagnosis of Ovarian Mucinous Cyst Adenocarcinoma during Emergency Caesarean Section - A Case Report
}

\author{
SALMA SULTANA
}

\begin{abstract}
:
Mucinous cystadenocarcinoma contribute about 10 to $20 \%$ of epithelial carcinoma ovaries. $A$ large Mucinous cystadenocarcinoma about $15 \mathrm{~kg}$ weight and about $25 \mathrm{~cm} \times 15 \mathrm{~cm} \times 10 \mathrm{~cm}$ size was found during emergency caesarean section due to obstructed labor in a primi gravida with term pregnancy. Right sided salpingo-ovariotomy with the mass was done. Per-operative no evidence of metastasis, other ovary was healthy. Histopathological report confirmed the diagnosis of well differentiated mucinous cystadenocarcinoma . The patient was referred to the National Institute of Cancer Research \& Hospital, Mohakhali, Dhaka. She was treated with 3 cycles chemotherapy (Inj.paclotaxel 250mg. 01+Inj.carboplatin 450mg $\times 02$ for 4 days 1st week, 3 days 2nd week, 2 days 3rd week). 3 months later, the patient was treated in Christian Medical College Vellore, Tamil Nadu, India, where interval debulking (total abdominal hysterectomy, left sided salpingo-oophorectomy with infra colic omentectomy) was done and another same 3 cycles chemotherapy was given. Further follow up in the same institute in India after 6 months revealed no abnormalities (C.T scan of the abdomen and pelvis - no evidence of intra abdominal adenopathy). Now the patient is symptom free for about two years (Last visit 3 months back).
\end{abstract}

Key words- Mucinous cystadenocarcinoma, caesarean section, primi gravida, salpingooophorectomy, chemotherapy.

\section{Introduction:}

Ovarian cancer is the 5 th most common cancer in woman and the 5th most frequent cause of cancer death. Primary ovarian cancer are epithelial, germ cell, sex cord and stromal origin. Epithelial tumors account for over $60 \%$ of all ovarian neoplasm and more than $90 \%$ of malignant ovarian tumors ${ }^{1}$. A case of mucinous cystadenocarcinoma, which was incidentally found during emergency caesarean section due to obstructed labor of a primi gravida with term pregnancy is presented in the article.

\section{Case Report:}

A 23 years primigravid patient was admitted in a private clinic of Noakhali with obstructed labour at term in February 2008. During emergency caesarean section a huge mass was noticed at right adnexal region. A healthy male baby of $2.75 \mathrm{~kg}$, apgar score 10 was delivered by lower uterine caesarean section. After closing the incision wound of the uterus, the mass was followed and found originating from right ovary. The mass was so large that it occupied right side of pelvis, loin, hypochondrium, under surface of liver and epigastrium. On palpation the mass was partly cystic and partly semisolid. The capsule was whitish, thick and intact. It was not possible to remove the mass intact through the incision of caesarean section. Then after puncture, debulking was done to some extent by suction of cyst contents. It was found loculated and full of thick mucinous material and was not possible to bring out all the content through suction. Then part of the content was removed manually. Right sided salpingo-ovariotomy with the mass was done. The mass was about $25 \mathrm{~cm} \times 15 \mathrm{~cm} \times 10 \mathrm{~cm}$ in size and contained mucinous material about 10 liters, removed through suction and manually. Measures were taken not to soil the peritoneal cavity. Peritoneal cavity was toileted with normal saline. The other ovary was healthy. No ascitis, no adhesion and no metastasis was seen into the surrounding structure. An initial staging was done \& it was found to be stage 1a ovarian carcinoma. Histopathological report confirmed the diagnosis of well differentiated mucinous cystadenocarcinoma. The patient was referred to the National Institute of Cancer 


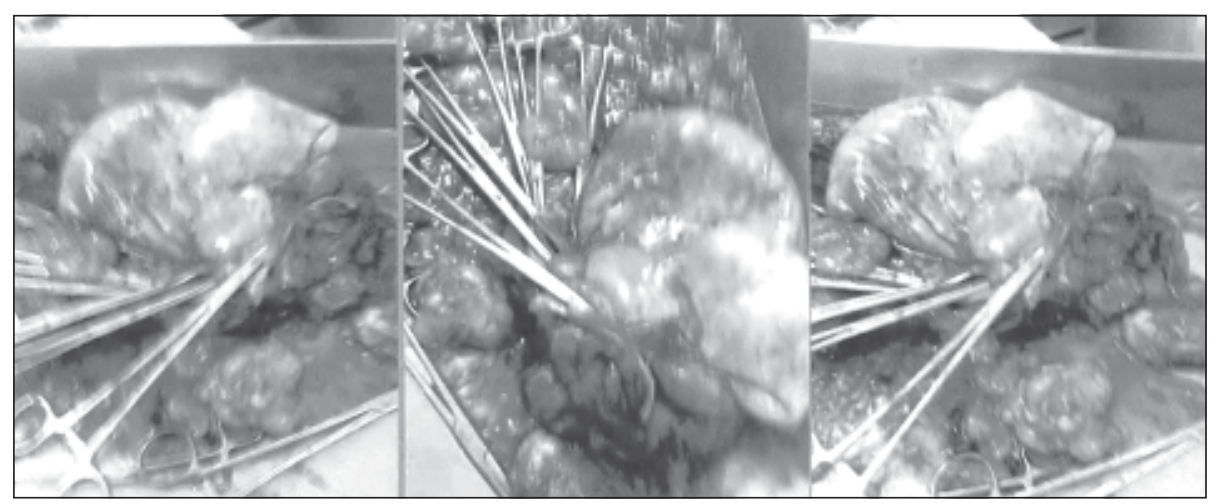

Per operative photograph of the tumor

Research \& Hospital. Post operative x-ray chest, ultrasonogram of the whole abdomen, liver function test revealed normal. Haematological report was within normal limit except raised ESR $70 \mathrm{~mm} / 1$ sthour \& immunochemistry CA125 was $29.9 \mathrm{U} / \mathrm{ml}$. She was treated with 3 cycles of chemotherapy (Inj.paclotaxel 250mg. $01+$ Inj.carboplatin $450 \mathrm{mg} \times 02$ for 4 days 1 st week, 3 days 2 nd week, 2 days in the 3 rd week). All the prognostic factors were in favor of the patient. Later on the patient was treated in Christian Medical College Vellore, Tamil Nadu, India. After 6 month's interval debulking (total abdominal hysterectomy, left sided salpingo-oophorectomy with infra colic omentectomy) was done and another same 3 cycles chemotherapy was given. Further follow up in the same institute in India on 24.12.2008 revealed no abnormalities(C.T.scan of the abdomen and pelvis -no evidence of intra abdominal adenopathy). Now the patient is symptom free for about two years (last visit 3 months back).

\section{Discussion:}

Mucinous cyst adenocarcinoma is a relatively rare ovarian malignancy comprising only 10 to $20 \%$ of epithelial derived malignancy. Nasu $\mathrm{K}$ showed the incidence of mucinous cystadenocarcinoma below the age of 40 was significantly higher than over the age of $40^{2}$. Ovarian carcinoma is classically present in middle aged woman ${ }^{3}$. In this case the patient was only 23 years old. This corresponds with the age incidence of ovarian mucinous cystadenocarcinoma. A patient with mucinous cystadenocarcinoma had a history of persistent ovarian tumor during her past three pregnancies ${ }^{3}$. A review of the literature reveals that carcinoma of the ovary fortunately remains a rare event during pregnancy ${ }^{5}$.This patient was a primi gravida. Presence of such large tumor (size $25 \mathrm{~cm} \times$ $15 \mathrm{~cm} \times 10 \mathrm{~cm}$ and about $15 \mathrm{~kg}$ ) indicated that she might had the tumor before pregnancy.

Different publications showed ovarian mucinous cystadenocarcinoma cases were incidentally diagnosed during emergency operation for twisted ovarian tumor and hysterectomy ${ }^{3,4}$. This case also was an incidental finding during emergency caesarean section of a termed primi gravita patient for obstructed labor. Usually these patient were diagnosed in very late stage, $75 \%$ stage III, stage I only as an incidental finding. ${ }^{4}$ This case also was incidentally diagnosed during emergency caesarean section but diagnosed in stage I.

Kurian AW found a positive relation of mucinous cancer to cigarette smoking6. Jordan SJ Green AC. in a systematic review showed that current smoking doubles a woman's risk of developing mucinous ovarian cancer. Stopping smoking returns the risk to normal in the long term ${ }^{7}$. But this patient was a nonsmoker. Blood group A and positive family history has a high risk of mucinous cystadenocarcinoma ${ }^{4}$. This patient had blood group A but no family history of ovarian mucinous cystadenocarcinoma.

Ultrasound, biochemical analysis of tumor marker and finally histopathology report confirm the diagnosis of a mucinous cyst adenocarcinoma. Colour dopler ultrasound enhances the diagnostic accuracy .Vaginal ultrasound - extremely valuable, gives exact measurement of the ovaries. Tumor marker CA 72-4 increases with the level of malignancy of mucinous tumor and the level of CA 72-4 is recommended to distinguish malignant from benign tumor ${ }^{8}$. Another tumor marker CA 125 has been shown to have a low sensitivity and specificity for detection of epithelial ovarian malignancy ${ }^{9}$. In a study by Inaba, mucinous cyst adenocarcinoma pregnancy specific protein (SPI) was present in $53.3 \%$ of cases, placenta specific 
proteins PP5 in 80\%, PP11 in $66.7 \%$ cases and these markers were suggested in monitoring patients with ovarian mucinous adenocarcinoma 10. In this case there was no antenatal checkup, so not diagnosed during early pregnancy. Biochemical analysis for tumor markers also were not done.

Treatment depends upon stage of the disease, associated with pregnancy or not. Surgery alone or followed by chemotherapy are the treatment options. Surgery may be simple salpingo-oophorectomy or more radical debulking operation may be needed according to stages of the disease. Nasu K. suggested conservative surgery as the treatment for the FIGO stage 1a grade 1 ovarian cancer ${ }^{2}$. According to Ayoubi $\mathrm{J}$, Elghaoui $\mathrm{A}$, management during pregnancy depends in great part on the gestational age and the stage of the malignancy. During the first 6 months immediate surgery is essential with sacrifice of the pregnancy except stage 1A. During the final 3 months, surgery is delayed until foetal maturity. This classical attitude is currently being questioned. Some teams feel that conservative treatment followed by chemotherapy is possible, thereby preserving the pregnancy 5 .

Huang HP, Fang CN, Kan YY. after exploratory laparotomy, gave chemotherapy (cyclophosphamide $500 \mathrm{mg} / \mathrm{m}$ 2and cisplatin $50 \mathrm{mg} / \mathrm{m}^{2}$ ) beginning at the second trimester of pregnancy for surgical stage $1 \mathrm{c}$ and reported satisfactory outcome ${ }^{11}$. Niwa K, Morishita $S$, reported a case of ovarian mucinous cystadenocarcinoma who received intra abdominal cisplatin five times following left oophorectomy, conceived and carried two pregnancies to successful deliveries at 34 and 37 weeks $^{12}$.

In this case of primi gravida, initial surgery during caesarean section was right sided salpingo-ovariotomy. Later on debulking operation (total abdominal hysterectomy, left sided salpingo-oophorectomy with infra colic omentectomy) was done in Christian Medical College Vellore, Tamil Nadu, India, after confirmation of diagnosis by histopathological report. In different articles chemotherapy (cyclophosphamide $500 \mathrm{mg} / \mathrm{m}^{2}$ and cisplatin $50 \mathrm{mg} / \mathrm{m}^{2}$ ) were used in ovarian mucinous cystadenocarcinoma but in this patient 3 cycles chemotherapy (Inj. paclotaxel $250 \mathrm{mg}$. $01+$ Inj.carboplatin $450 \mathrm{mg} \times 02$ à 4 days 1 st week, 3 days 2nd week, 2 days 3 rd week) were given in Bangladesh. Another same 3 cycles of chemotherapy were given in India after debulking opearation.
Well differentiated mucinous cystadenocarcinoma manifesting at stage 1 has excellent prognosis in most of the cases. Advanced stage of ovarian carcinoma typically show frank infiltrative type invasion, the prognosis is poor ${ }^{13}$. Patient with stage 1 a disease had no evidence of recurrence with in 5 years $^{2}$. This patient was diagnosed in stage la. Patient got adequate and proper treatment. Further follow up in the same institute in India after 6 months revealed no abnormalities (C.T scan of the abdomen and pelvis no evidence of intra abdominal adenopathy). Now the patient is symptom free for about two years (Last visit 3 months back).

\section{Conclusion:}

Accurate clinical staging and histopathologic assessment, satisfactory cytoreduction and effective adequate chemotherapy may affect the prognosis of ovarian cancer patients ${ }^{14}$.

\section{Referances:}

1. Oliver Dorigo MD, Vickl V. Baker MD Premalignant and malignant disorders of the ovaries and oviducts. Current obstetric and Gynecologic diagnosis and Treatment. 2003; 9: 933-34.

2. Nasu K,Hirotay. Clinical features of epithelial ovarian cancer in young reproductive woman. Nippon Sanka Fujinka Gakkai Zasshi. 1995; 47(9): 911-16.

3. Matsuyama T,Tsukamaton.Malignant ovarian tumor associated with pregnancy- Report of 6 cases. International Journal of Gynaecology and Obstetrics, Volume 28, Issue 1,January 1989; 28(1): 61-66

4. Monaghan J.M, Morrow CP. Malignant disease of the ovary. Dewhursts text book of Obstetrics and Gynecology for post graduates 6th Ed, 1999; p: 590.

5. Ayobi J,Elghaoui A. Ovarian cancer and pregnancy. Service de Gynecologic Obstetrique, Chula Grave, Toulouse. Revue française de gynécologie et d'obstétrique, 1995; 90 (7) : 33541.

6. Kurian AW. Histologic types of epithelial ovarian cancer: have they different risk factors?. Gynecologic oncology, 2005; 96(2): 520-530 
7. Jordan S.J,Green AC Does smoking increases risk of ovarian cancer ? A systematic review. Gynecologic oncology, 2006; 103(3): 1122-29.

8. Kikkawa F, Nagoya.Clinical characteristic and prognosis of mucinous tumors of the ovary. Gynecologic oncology, 2006; 103(1): 171-5.

9. Stankovic Z, Djuricic S.Epithelial ovarian tumors and CA -125 in premenarchal girls. European journal of gynaecological oncology, 2006; 27: 597-599.

10. Inaba N. Immunohistochemical detection of pregnancy specific protein (SP1) and placenta specific tissue proteins (PP5,PP10,PP11, and PP12) in ovarian adenocarcinomas. Oncodevelopmental biology and medicine : the journal of the International Society for Oncodevelopmental Biology and Medicine 1982; 3(5-6): 379-89.
11. Huang HP, Fang CN, Kan YY.Chemotherapy for mucinous cystadenocarcinoma during pregnancy: a case report. Europian Journal of Gynaecology \& Oncology. 2004; 25(5): 635-6.

12. Niwa K, Morishita S,Murase T. Successful pregnancy in a patient with pseudomyxoma peritonei arising from ovarian mucinous cystadenocarcinoma treated with cisplatin. . Gynecologic Oncology, Volume 59, Issue 3, December 1995, Pages :398-400

13. Acs G. Serous and mucinous (Low malignant potential) tumors of the ovary. 2005 American Journal of Clinical Pathology 2005; 123: S13S57.

14. Li MD. Analysis of long term prognostic factors of epithelial ovarian cancer. Ai Zheng (Chinese journal of Cancer), 2004; 23(11): 1306-10. 